ISSN: 2581-8341

Volume 04 Issue 10 October 2021

DOI: 10.47191/ijcsrr/V4-i10-26, Impact Factor: 5.825

\title{
Abdominal Distension after Myomectomy: A Case Report
}

\author{
Ayouche Othman ${ }^{1}$, ZakariaToufga $^{2}$, Asaad El Bakkari ${ }^{3}$, Rachida Latib $^{4}$, Youssef Omor ${ }^{5}$ \\ 1,2,3,4,5 Department of Radiology -National oncology institute -Mohamed V University-Rabat-Morocco
}

\begin{abstract}
We report the case of a 43-year-old woman who had a laparoscopic uterine fibroid resection, admitted for rapid progressive abdominal distention, and for whom MRI and histological examination confirmed the diagnosis of diffuse peritoneal leiomyomatosis. This begnin pathology is rarely described in the literature and its knowledge and important because of the pseudotumoral morphological appearance.
\end{abstract}

KEYWORDS: Abdominal Distension, Carcinomatosis, Leiomyomatosis, Myomectomy

\section{INTRODUCTION}

Diffuse peritoneal leiomyomatosis is a rare pathology of the smooth muscles of the peritoneal cavity, it is a benign pathology whose morphological aspect can evoke a malignant cause, the MRI is of great importance but the diagnostic confirmation is histological.

\section{CASE REPORT}

A 43-year-old woman was admitted in 2018 for resection of a large uterine fibroid laparoscopy, the operative follow-up was favorable and the pathological examination confirmed a uterine leiomyoma; one year after the patient consulted for abdominal distension with flank pain that had been evolving for more than 4 months, the clinical examination showed abdominal distension with diffuse pain on palpation, the biological examination was completely normal. An ultrasound showed the presence of a large hypoechogenic abdominopelvic mass, and the abdominopelvic MRI revealed the presence of a pelvic mass extended to the umbilical region and both flanks with a signal identical to the muscle one in T1 and T2 (figure 1,2) with a homogeneous enhancement after Gadolinium injection responsible for a discharge of the digestive organs without infiltrating them; a biopsy of the mass was made and the histological examination returned to favor diffuse peritoneal leiomyomatosis (figure 3 ).

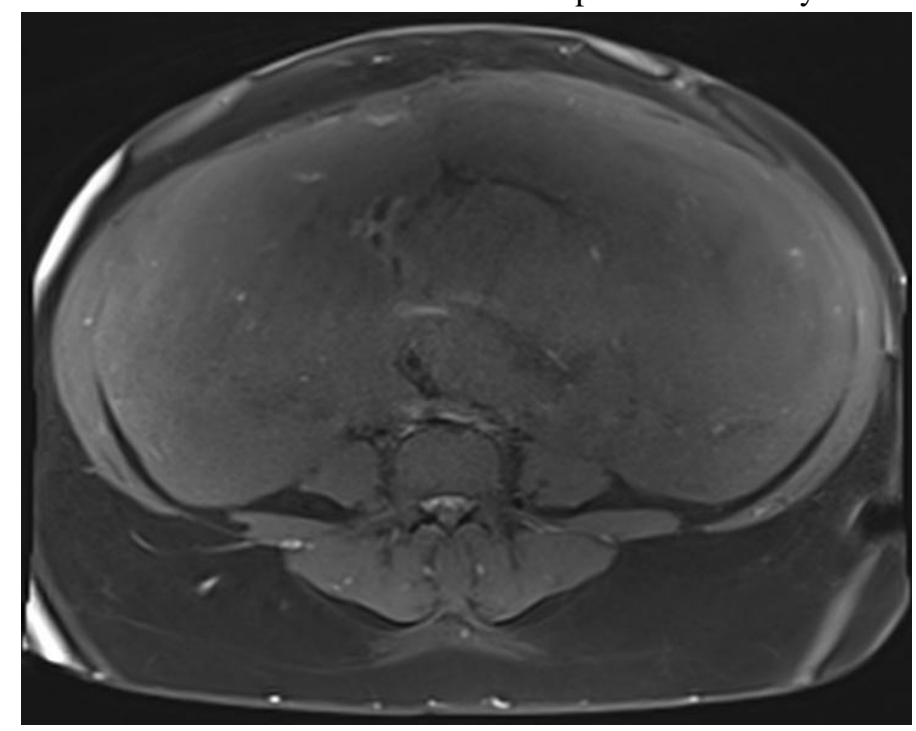

Figure 1: Axial section of abdominal MRI in weighted T1 sequence with fat saturation showing the large mass that is in the intermediate signal 


\section{International Journal of Current Science Research and Review}

ISSN: 2581-8341

Volume 04 Issue 10 October 2021

DOI: 10.47191/ijcsrr/V4-i10-26, Impact Factor: 5.825

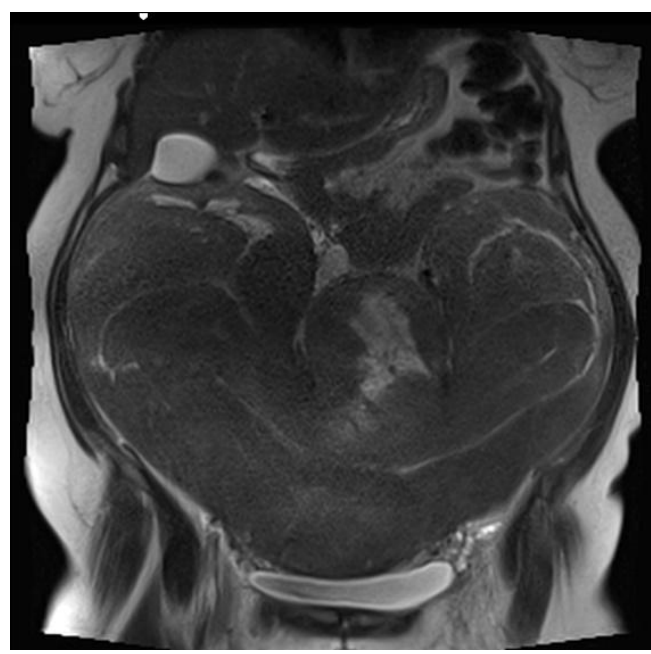

Figure 2: Coronal section of a pelvic abdominal MRI in a T2-weighted sequence confirming the same muscular signal with the repression of the digestive structures without infiltrating them.

\section{DISCUSSION}

Diffuse peritoneal leiomyomatosis is a benign and rare pathology of the smooth muscles of the peritoneal cavity; it was first described by Wilson and Peale in 1952, and so far fewer than 140 cases have been reported [1]; the etiology is undefined; two hypotheses are described in the literature [2-4], the first is during an estrogenic stimulation especially in pregnant women, during an oral contraceptive or in the carriers of secreting tumors; the second hypothesis as in our case is after a fibroid resection or hysterectomy for uterine fibroids; clinical symptoms vary from distention or feeling of abdominal heaviness to pain or rectal or vaginal bleeding; MRI plays a key role, it shows an isointense signal with the skeletal muscle in T1 and T2 with the possibility of a late homogeneous enhancement after injection of gadolinium[5], but the diagnosis remains purely histological.

The main differential diagnoses are peritoneal carcinomatosis and leiomyosarcoma.

The malignant transformation of LPD to leiomyosarcomatosis remains rare but described in the literature, it can be evoked in the presence of peritoneal nodules necrotic smooth outer margins or hepatic metastases [6,7].

Therapeutic management is still under discussion, conservative treatment is proposed for women who wish to procreate, including surgical castration or discontinuation of contraceptive pills, but if there is a high risk of malignant degeneration, more aggressive surgical treatment is recommended [8].

\section{CONCLUSION}

Diffuse peritoneal leiomyomatosis is a rare diagnosis not to be ignored and should be evoked in any patient with a history of myomectomy and who presents for an abdominal and pelvic mass.

\section{CONFLICT OF INTEREST}

No potential conflict of interest relevant to this article was reported

\section{REFERENCES}

1. Aydın, A., et al., Leiomyomatosis peritonealis disseminata in a nonpregnant woman. Turkish journal of obstetrics and gynecology, 2018. 15(4): p. 279-280.

2. Momtahan, M., M. Nemati, and A. Safaei, Disseminated peritoneal leiomyomatosis. Iranian journal of medical sciences, 2011. 36(1): p. 57-59.

3. Fasih N, Prasad ShanbhogueAK, Macdonald DB. Leiomyomas beyond the uterus: unusual locations, rare manifestations. Radiographics. 2008; 28:1931-48. 


\section{International Journal of Current Science Research and Review}

ISSN: 2581-8341

Volume 04 Issue 10 October 2021

DOI: 10.47191/ijesrr/V4-i10-26, Impact Factor: 5.825

IJCSRR@ 2021

Www.ijcsrr.org

4. Al-Talib A, Tulandi T. Pathophysiology and Possible Iatrogenic Cause of Leiomyomatosis Peritonealis Disseminata. Gynecol Obstet Invest. 2010;69:239-44.

5. Talebian Yazdi A, De Smet K, Antic M, Ilsen B, Vandenbroucke F, de Mey J. Leiomyomatosis peritonealis disseminata in a 50-year-old woman: imaging findings. JBR-BTR. 2010 Jul-Aug;93(4):193-5. doi: 10.5334/jbr-btr.284. PMID: 20957890.

6. Fulcher, A.S. and R.A. Szucs, Leiomyomatosis peritonealis disseminata complicated by sarcomatous transformation and ovarian torsion: presentation of two cases and review of the literature. Abdom Imaging, 1998. 23(6): p. 640-4.

7. Żyła, MM, Dzieniecka, M, Kostrzewa, M, Stetkiewicz, T, Wilamowska, A, Księżakowska- Łakoma, K, et al. Leiomyomatosis peritonealis disseminata of unusual course with malignant transformation: case report. Acta Obstet Gynecol Scand 2015; 94: 220- 223.

8. Psathas, G., et al., Leiomyomatosis peritonealis disseminata: A case report and meticulous review of the literature. International journal of surgery case reports, 2017. 40: p. 105-108.

Cite this Article: Ayouche Othman, ZakariaToufga, Asaad El Bakkari, Rachida Latib, Youssef Omor (2021). Abdominal Distension after Myomectomy: A Case Report. International Journal of Current Science Research and Review, 4(10), 14391441 